\title{
From ice to space: a greenhouse design for Moon or Mars based on a prototype deployed in Antarctica
}

\author{
Volker Maiwald ${ }^{1}$ (D) Vincent Vrakking ${ }^{1} \cdot$ Paul Zabel $^{1} \cdot$ Daniel Schubert ${ }^{1} \cdot$ René Waclavicek $^{2} \cdot$ Markus Dorn $^{1}$. \\ Lorenzo Fiore ${ }^{3} \cdot$ Barbara Imhof $^{2} \cdot$ Tomas Rousek $^{4} \cdot$ Vittorio Rossetti $^{5} \cdot$ Conrad Zeidler $^{1}$
}

Received: 16 October 2019 / Revised: 26 March 2020 / Accepted: 5 May 2020 / Published online: 16 May 2020

(c) The Author(s) 2020

\begin{abstract}
The future of human space exploration is aimed at long-term missions to Moon and Mars. Currently, plans are elaborated by NASA, ESA, CNSA and others for a return to the lunar environment within the next decade as an intermediate step towards the goal of reaching the surface of Mars. For sustenance and crew comfort the crew of such long-duration missions should be provided with fresh food on the lunar or Martian surface. Due to the associated power demand, the required resources and technological complexity, this is a major challenge for this kind of missions. To continuously provide fresh food without the need for cargo transfer from Earth towards Moon or Mars an on-site greenhouse system is required, producing the fresh food in situ. The associated effort and cost for all resources to be transported to the base of operation prohibit any waste of resources, requiring a system operating in a (nearly) closed loop. Developing and validating a prototype for an effective and efficient greenhouse, labeled future exploration greenhouse (FEG) for space exploration has been the goal of the EDEN ISS project, funded by the EU, in the past 4 years. This paper shows the results of a design elaboration of the FEG into a greenhouse for planetary deployment on Moon or Mars. Guided by lessons learned from operating the FEG in Antarctica for one year and based on assumptions concerning the mission scenario, e.g. assuming an existing base infrastructure on-site, the presented design incorporates a plant growth area which is more than a factor of two larger than the prototype. The total mass of the cylindrical system, including equipment required during launch, transfer and landing, is about $19 \mathrm{mT}$, fitting into a Falcon 9 launcher. The versatile design is compatible with a wide variety of mission scenarios, e.g. ESA's Moon Village, and currently public mission plans.
\end{abstract}

Keywords Human space exploration $\cdot$ Mars mission $\cdot$ Moon mission $\cdot$ Space greenhouse

Volker Maiwald

volker.maiwald@dlr.de

Vincent Vrakking

vincent.vrakking@dlr.de

Paul Zabel

paul.zabel@dlr.de

Daniel Schubert

daniel.schubert@dlr.de

René Waclavicek

rene.waclavicek@liquifer.com

Markus Dorn

markus.dorn@dlr.de

Lorenzo Fiore

fiore@arescosmo.it

Barbara Imhof

barbara.imhof@liquifer.com
Tomas Rousek

tomas.rousek@a-etc.net

Vittorio Rossetti

rossetti.vit@gmail.com

Conrad Zeidler

conrad.zeidler@dlr.de

1 German Aerospace Center (DLR), Institute of Space Systems, Bremen, Germany

2 Liquifer System Group (LSG), Vienna, Austria

3 Arescosmo S.P.A, Aprilia, Italy

4 XTEND Design Ltd., London, England, UK

5 VRdesign SPACE, Terracina, Italy 


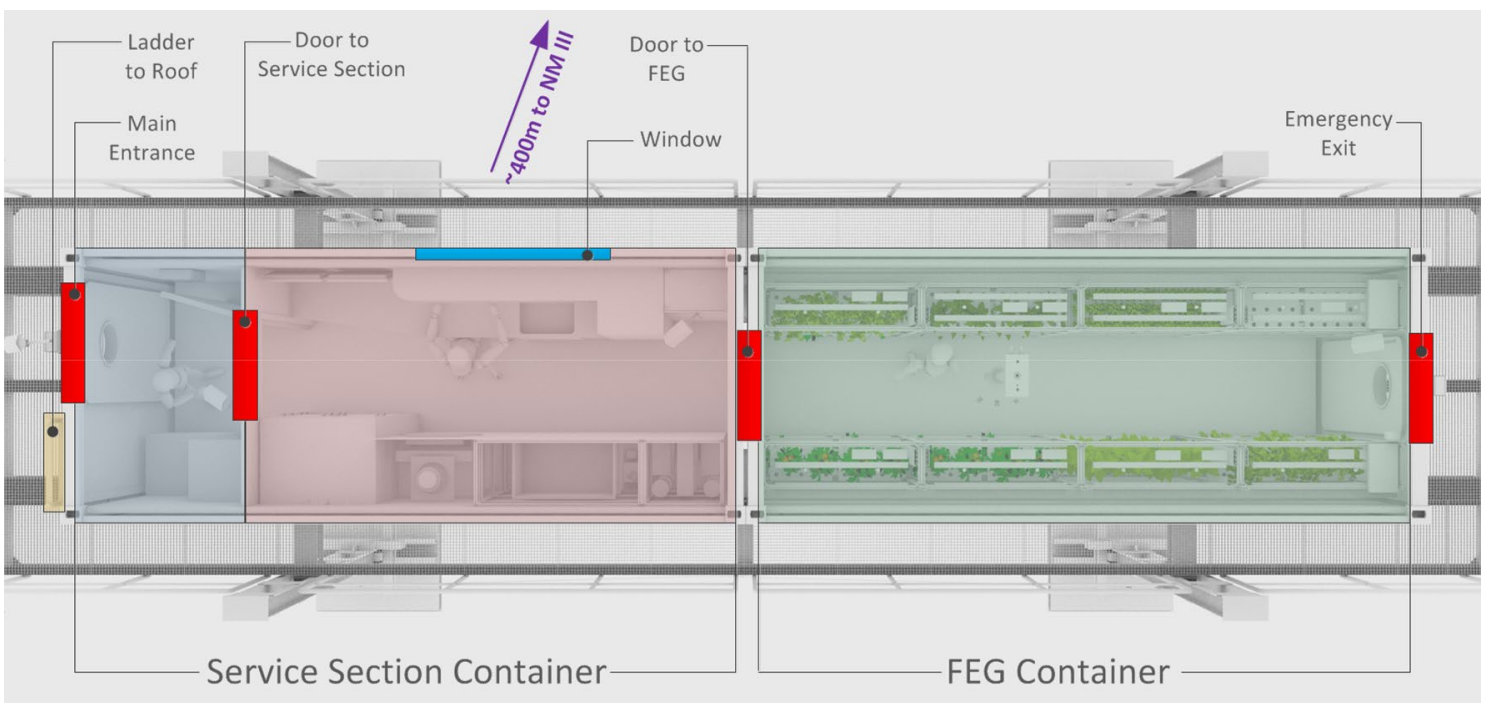

Fig. 1 Overview of the sections of the EDEN ISS mobile test facility: the service section and the future greenhouse (FEG), as deployed approx. $400 \mathrm{~m}$ south of the German Neumayer III Antarctic research station

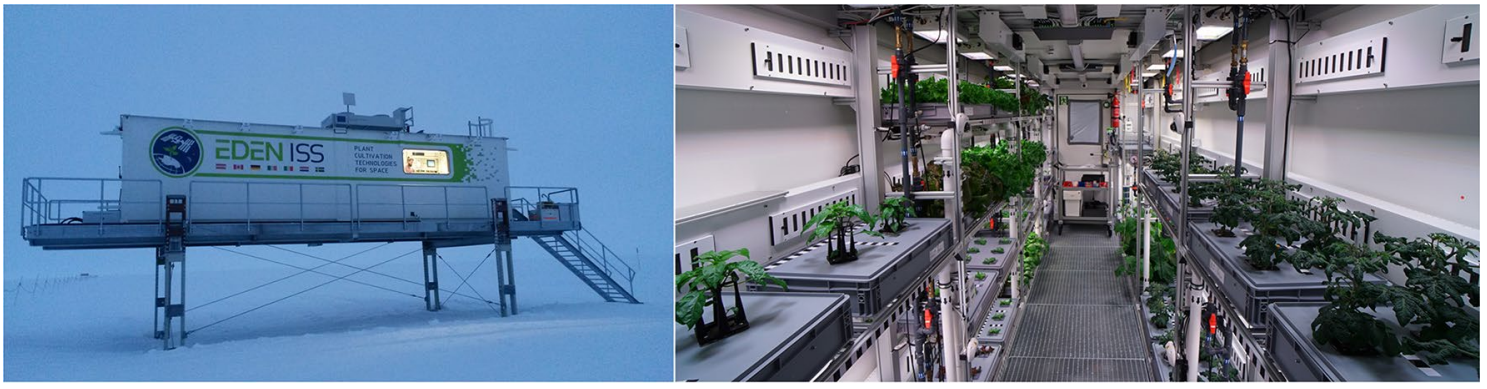

Fig. 2 An outside view of the MTF on its platform in Antarctica (left) and the FEG inside shortly after seeding (right). The interior holds grey boxes, which keep the plants in place and cover the aeroponic nutrient delivery system

\section{Introduction}

Various space agencies and nations have pronounced their intention of conducting human space exploration missions to the Moon, e.g. NASA with its Artemis programme. Long-term stays on the Moon or later Mars will require improvements in life-support and in general closed-loop technologies. One component of such a closed loop could be a greenhouse system for space.

\subsection{The EDEN ISS project}

EDEN ISS [1] was an EU funded project with the goal of developing and testing food production systems for human space exploration, e.g. on Moon and Mars. Within the project a prototype greenhouse system has been designed, developed and tested in Antarctica, near the German research station Neumayer III. The greenhouse system, dubbed mobile test facility (MTF), was deployed in Antarctica in January 2018, and has been in semi-continuous operation since February 2018.

The MTF consists of two main parts (see Figs. 1, 2), a service section (SES) and the actual greenhouse housing the crops, which is called future exploration greenhouse (FEG). Each of these main parts is installed in a dedicated 20 foot high cube shipping container. The SES has a working area and includes subsystems (e.g. air management, power management, control systems), as well as a so called "cold porch", which is essentially the equivalent of an airlock bridging the Antarctic outside and the container inside. Besides the working area and systems, the SES also held one experiment: A plant cultivation system based on the international standard payload rack (ISPR) format, which served as a prototype for a future on orbit 
food production system. This ISPR unit was returned to Europe after the first operations phase to facilitate further development and testing.

The FEG contains the actual growth area of the MTF, the seeding area and food production areas. In total eight racks containing various kinds of crops (e.g. tomatoes, salad, spices) are installed in the FEG. Besides that, all components required to supply the plants with nutrientsvia an aeroponic system-have been placed within the FEG, partially below the walking floor.

The FEG and SES are separated by a door, to reduce mixing of the atmospheres. The FEG also has an emergency exit at its rear.

Although the MTF was not the first space exploration greenhouse prototype, nor the first greenhouse in the Antarctic, it was the first greenhouse at the German Neumayer Station III and the first greenhouse to be tested in Antarctica with a space application in mind [2]. Antarctica is a suitable test bed, e.g. because of similar protocols concerning pollution (Antarctic environmental protection rules are similar to those for planetary protection) [2].

The MTF, as one of the newer greenhouse facilities to be installed in the Antarctic, incorporates more advanced controlled environment agriculture (CEA) technologies than most previous systems, utilizing the state of the art at the time of construction, including the technology developments pursued within the EDEN ISS project. Additionally, as the aim of the MTF is to serve as a test platform for closed-loop plant cultivation technologies and related procedures and operations, with an eye towards future bio-regenerative life support systems (BLSS), significantly more equipment has been installed to support data collection and remote control of the facility than would be the case for a more traditional greenhouse.

The plant cultivation is conducted with an aeroponic nutrient delivery system, which is a hybridization of classic nutrient film technique (NFT) and aeroponics. It has been developed by DLR and utilizes standardized $400 \times 600 \times 120 \mathrm{~mm}$ containers (growing trays, see Fig. 2), adapted covers and high pressure misting to achieve an appropriate degree of nutrient solution delivery and root zone oxygenation. Seeds are placed in rockwool cubes, which are then germinated in the dedicated germination trays. Once the juvenile plants have matured enough, the rockwool cubes are transplanted into 3D printed rockwool holders within the growing trays. The aeroponic system then periodically sprays the roots of the plants with a nutrient solution and the nutrient solution run-off within the trays acts as a nutrient film once the roots have developed sufficiently.

\subsection{Previous activities and remaining challenges}

The EDEN ISS MTF was not the first design for a space greenhouse developed by DLR and partners-the greenhouse module for Space project for ESA involved the design of a deployable, expandable system [3]. Equipped with a central core, holding four deployable spherical growth chambers, this system provides a total of $650 \mathrm{~m}^{2}$ of cultivation area.

Previous attempts at operating closed-environment systems are e.g. the closed ecology experiment facility (CEEF) [4]. The research goals concerning closed-loop habitation in space are only secondary, but the system provides room for a two-person crew and two goats. Typical experiments have durations from 1 to 4 weeks, i.e. shorter than required for an actual space mission.

The Lunar-Mars Life Support Test project [5] is another example of a technology test regarding food production under space conditions. The facility demonstrated $\mathrm{CO}_{2}$ removal via plant growth, in this case wheat.

Further examples are the European Micro-Ecological Life Support System Alternative (MELiSSA) [6], the Canadian controlled environment systems research facility (CESRF) [7], and the Chinese CELSS-experiment facility [8].

In the past, several experiments concerning plant growth in space have been conducted by major contributors in human spaceflight, e.g. Oasis 1 (1971), VEGGIE (2014) or the Advanced Plant Habitat (2018). VEGGIE is a food production facility for ISS. It is illuminated by an LED system and consists of several bellows, containing the actual plant growth areas. The bellows provide an enclosed volume, allowing the specific atmospheric conditions to be controlled. A root mat serves as basis for the plant growth. The produced food is used as supplement for the main food supply of the ISS crew [9].

More details about actually flown hardware and a comparative analysis can be found in [9].

Several greenhouses - of various configurations-have been operated in Antarctica, yet not for the purpose of analog testing of space hardware. One example is the South Pole Food Growth Chamber, located at the Amundsen-Scott South Pole Station. It has been used to supply fresh food, e.g. cucumber, pepper, lettuce, or tomatoes [10], to the station's crew. It consists of two parts: a utility section and the actual growth area, separated by a glass wall. The growth area consists of a plant production section and an environmental chamber, which is also used for relaxation of the crew [2].

Depending on the exact size, the caloric value of the grown food is likely to be insufficient for crew nutrition. Yet, they can add comfort and certain nutrition components, which are essential. There are however key challenges with respect to the implementation of such systems. The 
micro-biological environment is still an unknown field for such closed food production systems and how the plants react to a spacecraft system with its special environment, including contaminants. If tested in micro-gravity environment (such as the ISS), food production systems should be scalable and adaptable to use on planetary surfaces. This is challenging due to the different gravitational situations [11]. Analysis of existing systems for LEO application shows that these systems are not suitable for long-term missions ( $>5$ years) [12]. Yet, food production facilities are expected to be more mass demanding, have a high power consumption and need crew attendance [13].

Another aspect concerns the usage of food production facilities as a component of life-support systems. Integrating the plants into the system is not yet fully understood, especially the repercussions of the life-support system on the plant growth. An example is usage of biocides for water sanitation (i.e. keeping the water potable for the crew) - how does this affect the plant health and food quality? [11].

Including system autonomy, e.g. also via robotics, is a system design challenge; subsystem volume and compactness need to be addressed as for any space system [11].

Plant selection is also no trivial tasks. Figures of merit like yield and nutritional value need to be optimized via plant selection [11].

Nutrient delivery, waste handling or recycling and how to cook the produced food are all aspects that are further linked to greenhouses for space [11]. To limit the effort for food production, ready-to-eat crops (e.g. cucumbers) are at an advantage [14].

\subsection{The EDEN ISS mission}

EDEN ISS officially started as a project in March 2015. Initially the project focused on the design-using Concurrent Engineering studies [15] — of the greenhouse. Subsequently, subsystem components, e.g. the aeroponic nutrient delivery system, were set up in a laboratory for testing and development, before being installed in the greenhouse.

Between October 2016 and October 2017, the EDEN containers were assembled at DLR and all subsystems installed for testing. A complete growth cycle of crops was conducted, showing all components to be operational.

Subsequently, the greenhouse was disassembled and prepared for shipment to Antarctica, where it arrived in January 2018. A platform had been set up there, $400 \mathrm{~m}$ south of Neumayer Station III. The platform can be raised to account for snow accumulation over time. The two single containers were deployed on the platform and connected. Installation of the subsystems commenced and in February 2018 the greenhouse started operation.

Although the self-contained, 'closed', nature of the MTF allows for remote monitoring and control operations basically anywhere on Earth, and indeed the facility could have been and was tested for some time in Germany, there are a number of aspects related to an Antarctic deployment which offer valuable insights into future space applications.

First of all, shipments and travel to the Antarctic are only possible during the Antarctic summer season, roughly from November until March each year. As such, a conservative approach to spares and consumables is needed to mitigate potential failures, but inevitably a degree of flexibility is needed within the design, and on the part of the on-site and remote operators, to cope with unforeseen problems, similar to what will be required for future planetary bases.

Second, the operational aspects of monitoring and controlling the greenhouse can be considered fairly analogous to future space missions. The available bandwidth for communication and telemetry towards the remote monitoring sites is quite limited and as such, although not impacted by the same time delays, is relatively similar to the constraints faced by an actual space missions. The overwintering crew of the Neumayer III station also acts as a reasonable approximation of an astronaut crew, being trained though not expert operators of the facility and having similar constraints on their availability.

Additionally, the environmental conditions, the low biodiversity, the isolation, and small crew size at Neumayer III, in particular during the winter season, lend itself to key investigations into the potential psychological benefits of the greenhouse.

EDEN ISS was operated mainly by a crewmember of the EDEN ISS team at Neumayer III, until December 2018. About $268 \mathrm{~kg}$ of fresh produce were harvested from the greenhouse, during the first operations phase between 7 th February and 20th November. A detailed breakdown of the overall yield is provided in Table 1. Crop selection occurred based on a method described in [14]. Criteria for selection have concerned the human factors, cultivation and yield. Measurements concerning nutrition values are currently still being analyzed and will be published at a later time.

Leafy greens consisted of Swiss chard, red mustard and rocket, while the selected lettuce cultivars were Expertise, Outredgous, Batavia and Waldman's green. The herbs grown during the first operations phase were chives, mint, parsley and basil. Two varieties of cherry tomatoes were grown. Sweet pepper, although successfully grown during the test phase in Germany, did not perform as well in the Antarctic, only producing some small amount of fruits near the very end of the operations phase. The cause for this is currently unclear and still being investigated.

Supplementary experiments involved investigating the micro-biological environment in the greenhouse and e.g. the food quality/safety.

A more detailed account of the greenhouse and its mission can be found in literature [16]. The MTF continues to 
Table 1 Crop yield during Eden ISS' 286 day analogue test at Neumayer III from 7th February to 20th November 2018

\begin{tabular}{lll}
\hline Crop & Edible biomass $(\mathrm{kg})$ & $\begin{array}{l}\text { Average edible } \\
\text { biomass }(\mathrm{kg} / \\
\text { day) }\end{array}$ \\
\hline Lettuce & 56.4 & 0.197 \\
Leafy greens & 50.5 & 0.177 \\
Cucumber & 66.8 & 0.234 \\
Tomatoes & 46.2 & 0.162 \\
Kohlrabi & 18.8 & 0.066 \\
Radishes & 8.2 & 0.029 \\
Sweet pepper & $0^{\mathrm{a}}$ & 0 \\
Herbs & 15.0 & 0.052 \\
Total & 261.9 & 0.916 \\
\hline
\end{tabular}

Listed is the fresh edible biomass (nutrition values are still under analysis and will be published at a later point in time)

${ }^{a}$ Why sweet pepper did not produce meaningful yield is currently still being investigated.

operate at the Neumayer Station III, with on-site operations carried out by the regular overwintering crew of the station, with remote support from the EDEN ISS team.

\subsection{Scope of paper and objectives}

The goal of the EDEN ISS project was to develop and test a prototype of a space greenhouse. The MTF has been successfully tested in Antarctica and is currently still in operation, allowing for further research.

This paper addresses the "delta" between the terrestrial prototypes, the MTF, vs. the actual greenhouse to be deployed in a space environment, i.e. Moon and Mars. The work presented herein was part of the project, to describe and layout a greenhouse system based on the design operated in Antarctica, modified by lessons learned and the requirements of a space environment. It consists of an extrapolation from the current state of the prototype to a feasible space greenhouse, which will be further developed in coming years.

As a greenhouse will always be part of a larger infrastructure on Moon or Mars, resp. embedded into a mission architecture, and such infrastructure/ architecture currently does not exist it is required to make assumptions to create a closed mission scenario for this design. These are explained in Sect. 2.2 and discussed in Sect. 3.5.

While plans for a return to the lunar environment (NASA's Artemis and LOP-G, ESA's Moon Village) are on the table, they are not concrete enough to derive detailed requirements for a suitable greenhouse. Nonetheless, a mission scenario has been set up, serving as a basis for the further technical design.
This paper presents the result of this design work, describing a space greenhouse, which is:

- Technically feasible,

- Derived from an existing, terrestrial prototype, and

- Improved by technical and operational lessons learned.

The paper explains the approach of the design work and the respective assumptions, especially concerning scaling of the EDEN ISS greenhouse subsystems.

It will report on relevant lessons learned from the EDEN ISS project and how these have impacted the design for a possible space greenhouse.

A listing of the most relevant requirements will be provided, to address the envelope the results have been subject to. The structure concept, e.g. frames and shells, will be presented as well as the accommodation of subsystems.

This paper aims not at providing a single truth about a greenhouse design, but at providing information about a possible, feasible greenhouse design, founded in the actual operation of a greenhouse prototype, tested in a harsh environment. EDEN ISS cannot be applied directly to a space mission, but it can serve as useful stepping stone towards an operational lunar or Martian greenhouse.

Summarizing, the objectives of the paper are: 1) Presenting the approach for deriving a feasible planetary greenhouse from an analog tested prototype. 2) Providing system requirements and an overview of the system design, embedded in an assumed mission scenario (as currently no definite mission scenario exists within the community). 3) Compare the results with existing mission plans to discuss their fit. 4) State open issues to describe the limits of the extrapolation.

These steps are undertaken to establish the feasibility of the derived design from a technical and mission scenario point of view.

\section{Method}

The basic approach for the study has been Concurrent Engineering [15], as used by ESA for about two hundred space mission designs ${ }^{1}$ as well as DLR (currently more than 70 studies have been conducted with that method). DLR has extensive experience in designing crewed space systems using Concurrent Engineering, e.g. through a series of studies evolving the design of a Post-ISS platform in Low Earth Orbit [17].

Concurrent Engineering is an iterative process, where a design team covering all relevant disciplines (e.g. structure,

\footnotetext{
$\overline{1}$ https://www.esa.int/Enabling_Support/Space_Engineering_Techn ology/CDF/ Studies_Reviews.
} 
Table 2 Objectives for the design study presented here

\begin{tabular}{ll}
\hline Objective & Description \\
\hline $\begin{array}{l}\text { Incorporation of lessons learned into the design, especially concerning } \\
\text { system performance, crop yield, crew acceptance and contamination }\end{array}$ & $\begin{array}{c}\text { Technology and experience derived from MTF design and operation } \\
\text { will be elaborated and integrated into an advanced design and recom- } \\
\text { mendations for applications to long duration space missions } \\
\text { Create mass and volume budgets for the design }\end{array}$ \\
$\begin{array}{l}\text { Derive technical system budgets } \\
\text { Analyse feasibility of the design for planetary deployment }\end{array}$ & $\begin{array}{l}\text { Regard transfer to the planetary surface, crew needs, safety and risks } \\
\text { A structural design shall be created with special focus on internal } \\
\text { accommodation }\end{array}$ \\
$\begin{array}{c}\text { The frual design shall include considerations about envelope under } \\
\text { the fairing, and set-up of the module on site } \\
\text { Include considerations about which components are required for subsys- } \\
\text { tems and general operation of the greenhouse }\end{array}$ \\
\hline
\end{tabular}

mechanisms, systems, thermal control) conducts a thorough analysis of the study object. Basis for the method is next to the design team, a common data model. The advantage of Concurrent Engineering is consistency in the design, as any design challenges can be addressed by the design team simultaneously. For more details the reader is referred to $[15,17]$.

Based on the EDEN ISS mission experience and design of the original greenhouse, the design team created an adapted design for a space greenhouse.

Aside from the operational environment, the major change for the design is an increase of the original $12.5 \mathrm{~m}^{2}$ growth area to at least $25 \mathrm{~m}^{2}$ of growth area.

\subsection{Study approach}

The design study was initiated with preparatory work (e.g. collecting lessons learned), before the design team assembled for the detailed design. Preliminary analysis was focused on possible designs for a deployable greenhouse structure, evaluation of MTF mission performance, requirements, possible mission scenarios for evaluating and establishing feasibility and crop yield.

As a first step, based on typical systems engineering guidelines, we established the User Needs [18]/Stakeholder Expectations [19], in the form of lessons learned from operating the prototype greenhouse in Antarctica. Based on these, requirements were defined to address the needs.

As a further branch of constraints, the mission scenario was elaborated, as a concept of operations [18], also driving the design in conjunction with requirements. It is described in Sect. 2.2.

As a second step, the structure and subsystem designs were set up. A first draft of the complete design was crosschecked with requirements and the desired performance.

Gaps were identified and the design adapted, iteratively until all requirements were met and feasibility was established.

For this purpose, a major driver has been the sub-system accommodation, which limited the greenhouse's available growth area. A calculation was set up to link the subsystem volume with the growth area to determine the latter, basically maximizing it within the constraints given by the requirements. This calculation is provided in Sect. 2.3.

A total of five objectives, shown in Table 2, drove the study. All have been fulfilled by the end of the study time.

\subsection{Design assumptions about mission scenario}

The basic premise about the design is that the greenhouse should be derived from EDEN ISS' MTF, and should share its basic operational principles, e.g. usage of aeroponics for nutrient delivery. Also the basic layout, containing a service section and the actual greenhouse area has been assumed to remain. The latter has been assumed to be deployable.

The design did not encompass further base components. The following assumptions about the mission have been made:

1. Existing infrastructure on site: An existing infrastructure/base is on site before deployment of the greenhouse. This base provides power, thermal control (i.e. heat transport to the base's exterior), life-support for the crew (outside the greenhouse, and especially transferring materials, e.g. $\mathrm{CO}_{2}$, between greenhouse and main base) and construction tools and robotics for setting up the greenhouse.

2. Existing infrastructure for launch and transfer: The Space Launch System is currently planned as launcher for lunar missions, supported by commercial launchers, e.g. Falcon 9. As SLS has a limited availability, for the greenhouse design presented here a Falcon 9 has been assumed as baseline launcher (with a LEO launch mass of $22,800 \mathrm{~kg}$ setting the launch mass requirement), where necessary a Falcon 9 Heavy could serve as a backup. As construction of a lunar base would require repeated transfer of base components, it has been assumed that a transfer vehicle exists to transport modules from LEO to the target. During transfer the 
Table 3 Calculation of sizing based on an assumed increase of factor 2 for the growth area and scaled to the actual design growth area of 30.8 $\mathrm{m}^{2}$

\begin{tabular}{|c|c|c|c|c|}
\hline Subsystem & $\begin{array}{l}\text { Area for EDEN ISS } \\
\left(S_{0}\right)\left[\mathrm{m}^{2}\right]\end{array}$ & $\begin{array}{l}\text { Factor for doubled } \\
\text { growth area }\end{array}$ & $\begin{array}{l}\text { Area for doubled growth } \\
\text { area }(S)\left[\mathrm{m}^{2}\right]\end{array}$ & $\begin{array}{l}\text { Actual } \\
\text { volume } \\
{\left[\mathrm{m}^{3}\right]}\end{array}$ \\
\hline Nutrient delivery system (NDS) & 0.9 & 1.5 & 1.35 & 4.52 \\
\hline Air management system (AMS) & 0.9 & 2 & 1.8 & 6.02 \\
\hline Thermal control system (TCS) & 0.48 & 1.5 & 0.72 & 2.41 \\
\hline Power control and distribution system (PCDS) & 0.4 & 1 & 0.4 & 1.34 \\
\hline Command and data handling system(CDHS) & 0.2 & 1 & 0.2 & 0.67 \\
\hline \multirow[t]{2}{*}{ Total } & 2.88 & & 4.47 & \\
\hline & Gradient (m) & Growth area $\left(\mathrm{m}^{2}\right)$ & EDEN ISS volume $\left(\mathrm{m}^{3}\right)$ & \\
\hline System volume & 0.27984 & 30.8 & 6.336 & 14.96 \\
\hline
\end{tabular}

greenhouse is protected against debris and radiation by a cover, which would be shed for deployment.

3. A docking stage controls the greenhouse module's attitude and position: For launch and transfer (incl. docking with the transfer vehicle) it is assumed that a docking stage is attached to the greenhouse during launch, enabling the module to be a passive target for docking of the transfer stage. This stage will control the position and attitude.

4. All sub-systems are pre-installed in the module's service section, further equipment is stowed in the deployable part: To minimize workload on the crew and downtime of the greenhouse as well as for efficient usage of the launcher, no subsystem in the service section shall require installation after launch.

\subsection{Rescaling of greenhouse sub-systems for growth area calculation}

The MTF and its subsystems served as starting point concerning the subsystems of the space greenhouse, with scaling applied, where necessary. Based on the scaling of subsystems, and with the given constraints concerning size, this provided the growth area available in the greenhouse.

For system sizing concerning their volume, resp. area, the baseline has been the FEG. As a first step, the system scaling factors were determined for an increase of factor 2 for the growth area. From this, the gradient for generic system sizes could be determined. The basic assumption has been that the available height is $2.2 \mathrm{~m}$, similar to the EDEN ISS MTF.

Depending on the exact subsystem, different scaling factors have been set for the growth area increase of factor 2 , based on the actual system design. It is assumed that a doubled cultivation area requires the AMS to handle twice as much air flow and therefore the system needs to be doubled in size. The NDS and the TCS on the other hand do not need to be increased by a factor of two. The increased capacity demand for those systems does not necessarily mean a doubled size (e.g. an NDS pump with twice as much flow rate is not twice as large). Consequently, a factor of 1.5 was chosen. The PCDS and CDHS remain the same size, because those systems are, to a large degree, independent of the cultivation area. A summary of the scaling factors is shown in Table 3.

The last row shows the calculated volume gradient, the actual growth area of the design, the original volume of the FEG and the subsequent total subsystem volume for the presented design. The last column shows the individual proportions based on the respective factor

As a similar height is available for all subsystem volumes, only areas are used for the calculations as simplification. From these (together with the height of $2.2 \mathrm{~m}$ ) the actual volumes for each subsystem can be calculated, which are shown in the fourth column of Table 3 . From the total areas, a gradient can be calculated, which is presented in the second column of the last row.

The gradient $m$ for the system volume increase can be calculated by:

$$
\begin{aligned}
m & =2.2 \mathrm{~m} \cdot\left(S-S_{0}\right) /\left(A-A_{0}\right) \\
& =2.2 \mathrm{~m} \cdot\left(S-S_{0}\right) / A_{0} .
\end{aligned}
$$

The gradient has the unit of meters and depends on the subsystem area of the original EDEN ISS MTF $\left(S_{0}\right)$ and the new design $(S)$ as well as the growth area of the EDEN ISS MTF $\left(A_{0}\right)$ and the assumed growth area of twice that (A). Equation (1) simplifies to just containing $A_{0}$ because of $A=2 A_{0}$.

With the original growth area of $12.5 \mathrm{~m}^{2}$ the gradient can be calculated to $0.27984 \mathrm{~m}$.

Together with the actual growth area of the design, shown in the next column of Table 3 , this provides the subsystem volume in the following manner: 
$V=m \cdot A+b$.

Here, $V$ is the volume, $m$ is the gradient $(0.27984)$ explained previously, $A$ the actual growth area $\left(30.8 \mathrm{~m}^{2}\right)$ for the new design and $b$ the ordinate stemming from the original design, i.e. the overall subsystem volume of the MTF $\left(6.336 \mathrm{~m}^{3}\right)$. To receive the actual volume of the respective subsystems, the area (as the height is similar) is taken into account. The subsystem's area for the doubled growth area is related to the total area of all subsystems, thus receiving their ratio of the volume.

The respective volume was then considered for the actual design, fitting these volumes into the service section of the greenhouse module.

For the calculations the following assumptions have been made:

1. The internal diameter of the service section is $4 \mathrm{~m}$,

2. The internal diameter of the greenhouse's growth area, when deployed, is $5 \mathrm{~m}$, and

3. A corridor of $1.2 \mathrm{~m}$ is available to traverse the service section

The mass budget was established with an extensive parts list for each subsystem, based on the existing MTF design and the changes which were implemented based on lessons learned.

Where data was lacking, estimates have been made based on the scaling of the existing subsystem.

\subsection{Designing the structure}

In order to provide a significant cultivation area, and to accommodate larger crops such as tomatoes and cucumbers, a greenhouse needs to provide a large internal volume, beyond what can be encompassed in currently available launcher fairings. As such, it is necessary to send either multiple small greenhouse modules, or design a system which can be deployed to provide the needed volume. The drawback to this is that it requires that internal equipment is deployable as well, or, where this is not feasible, additional effort is required post-deployment for outfitting of the facility.

The approach used in the EDEN ISS MTF, which aimed to separate the technical subsystems from the plant cultivation area to the extent possible, leads to a natural division in the primary structure between a rigid, non-deployable service section and a deployable greenhouse area.

A significant number of studies have been carried out by the EDEN ISS partners with respect to greenhouse and habitat shape factors and design aspects.
In this case, as the design is intended as an adaptation of the existing MTF, the most applicable solution was to utilize a cylindrical shape for the structure, which would preserve the overall layout and directionality of the MTF design, while adapting it to better suit to launcher payload envelopes as well as the expected pressure loads during a Moon or Mars mission.

Once the shape was fixed, the partners investigated existing concepts and systems, in particular for the deployable section, to gather the necessary information related to, among others, mass estimation, deployment mechanisms, packaging efficiencies, and material and layer design.

This led to an initial structure design, which was then iterated repeatedly in a feedback loop with the internal configuration and subsystem design.

\section{Results}

The overall system layout of the greenhouse can be seen in Fig. 3. It is clearly visible that the greenhouse is divided into a service section, where the subsystems, e.g. power distribution, air filtration and the nutrient delivery system, are located and a deployable part, where the growth area allows food production and contains all relevant equipment, e.g. air ducts.

Based on the calculation approach in Sect. 2.3, the growth area has been calculated to $30.8 \mathrm{~m}^{2}$ with a total subsystem volume of approx. $15 \mathrm{~m}^{3}$. As the calculations occurred iteratively, the results have already been mentioned in Sect. 2.3.

\subsection{Lessons learned}

The EDEN ISS MTF is a prototype planetary greenhouse. Its operation in Antarctica can provide relevant information about reasonable design and processes for a similar human spaceflight system. Therefore, a first step for the design work has been to collect lessons learned stemming from the Antarctic operations phase during EDEN ISS. These lessons have then been incorporated into design decisions and requirements alike. They are listed in Table 4.

With the exception of LL-002, which concerns the operation of the greenhouse, all lessons affect the design of the greenhouse.

To respond to the first two lessons a system similar to a washing machine has been introduced into the service section of the greenhouse module. The trays, which hold the plants, can thus be cleaned directly in the greenhouse, which reduces effort for the crew-no transfer to other parts of the base is necessary.

The corridor in the service section has been enlarged in comparison to the original corridor in the MTF. This has been achieved in part by relocating the working desk from 

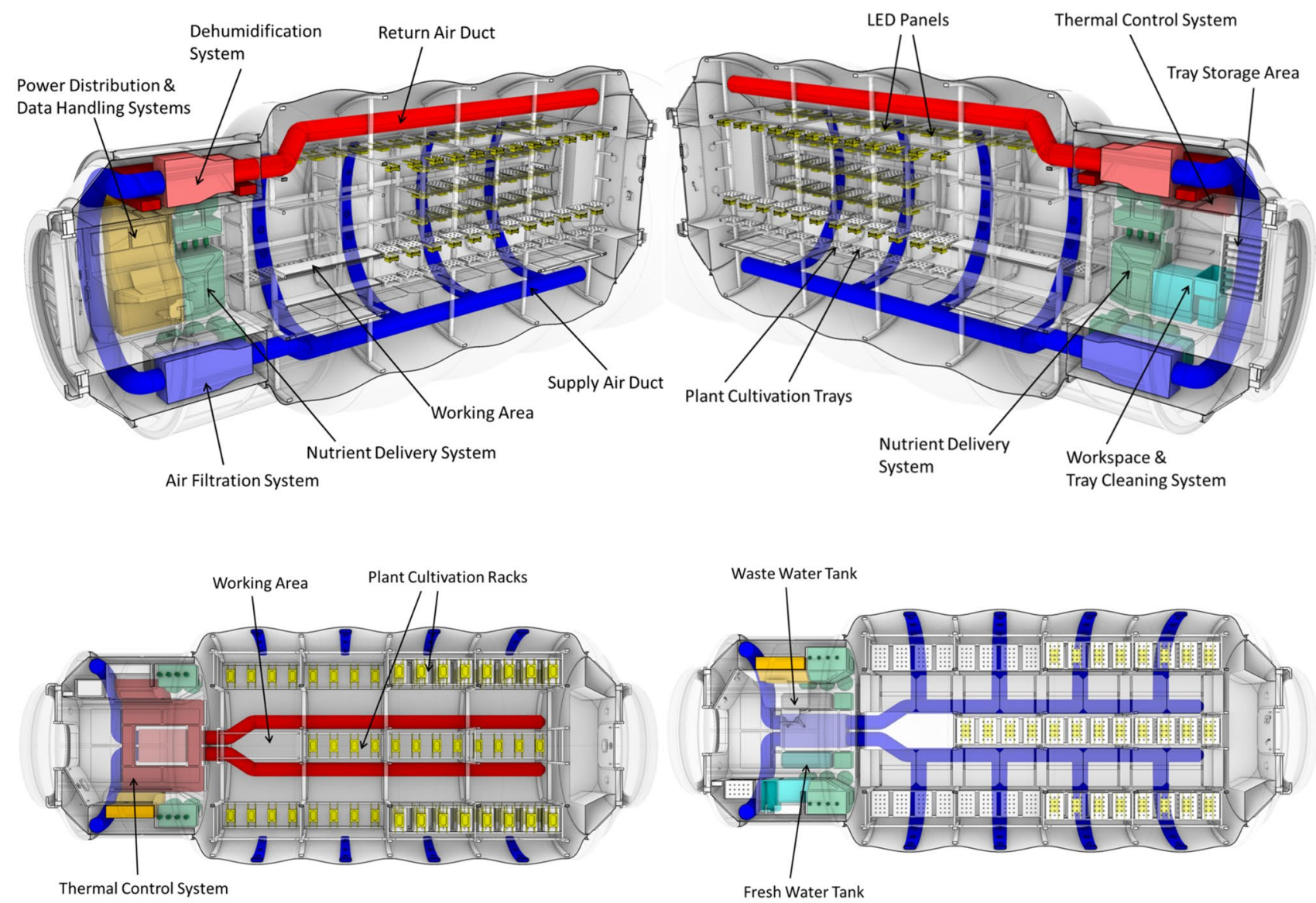

Fig. 3 Cross-section view of the greenhouse with the subsystems as installed in the service section and the deployed greenhouse (top) and top view and bottom view of the greenhouse presenting the overall configuration (bottom)

the service section to the greenhouse section (which also allowed increasing table size). The piping (water, nutrients) has been replaced from the sub-floor to the area below the plant racks. The floor is now below the pipes, granting better access for maintenance and cleaning.

The greenhouse shape has been changed from rectangular to cylindrical, accommodating the launcher fairing. A cold porch and window do not apply for the planetary greenhouse, and therefore they have been removed from the design.

The racks have been designed to be modular so the configuration can be altered during operation depending on the requirements of the space mission. All piping has been arranged in a way to prevent the formation of bubbles, requirements have been included conform to lessons LL-011 and LL-015.

The atmosphere management system (AMS) has been enlarged, as was the thermal control system (TCS), improving accessibility. A mobile ladder system, similar to a library's, has been implemented in the planetary greenhouse to improve access to the different cultivation levels, while at the same time limiting obstruction of the corridors when not in use.

\subsection{Requirements}

Over forty requirements on the mission and system have been collected during the study, the majority impacting the system design and performance. The most important, design relevant, requirements are listed here:

MI-DE-0010: The greenhouse system shall be launched with a single launch.

SY-DE-0010: The service module subsystems shall be pre-installed before launch to allow operation; only interface connection shall be required.

SY-DE-0020: The system shall fit into an envelope of $4 \mathrm{~m}$ in diameter and $6.6 \mathrm{~m}$ length during launch.

SY-DE-0030: The system shall have a thermal and electrical interface to the main habitat, allowing power transfer and thermal heat load transfer.

SY-DE-0050: The system shall be operational for 2 years without resupply. 
Table 4 Lessons learned about the design and operation of the EDENISS MTF

\begin{tabular}{|c|c|c|}
\hline Number & Title & Description \\
\hline LL-001 & Sink too small & $\begin{array}{l}\text { Too small for plant tray cleaning, water spillage regularly occurring, } \\
\text { include a dedicated tray cleaning and checkout system }\end{array}$ \\
\hline LL-002 & Plant tray cleaning has to occur in EDEN Container & transfer from greenhouse to station requires too much effort for cleaning \\
\hline LL-003 & Work desk too small $\left(0.75 \mathrm{~m}^{2}\right)$ & $\begin{array}{l}\text { Seeding difficult (tray for seeding + container for seeds), sampling, twice } \\
\text { the area required (possibly foldable); each week at least once seeding, } \\
\text { sampling twice per week, cleaning of NDS tanks difficult; if possible: } \\
\text { foldable }\end{array}$ \\
\hline LL-004 & $80 \mathrm{~cm}$ corridor service section too small & $\begin{array}{l}\text { For repairs, including second crewmember and equipment; } 1 \mathrm{~m} \text { at least, } \\
\text { where possible increase of area (e.g. via foldable tables), opposite of } \\
\text { subsystem access more room required (at least subsystem size + room } \\
\text { for manipulation/ equipment) }\end{array}$ \\
\hline LL-005 & FEG corridor size is sufficient & \\
\hline LL-006 & Subfloor: good idea, positioning has to be re-evaluated & $\begin{array}{l}\text { If floor-plate is removed, no room for positioning, accidental stepping on } \\
\text { pipes risky }\end{array}$ \\
\hline LL-007 & Piping and harness has to be rearranged for cleaning & "Large scale"-cleaning has to be feasible \\
\hline LL-008 & Cold porch sizing ok & For two people sufficient, for 4 people insufficient \\
\hline LL-009 & Window has strong thermal effect & $\begin{array}{l}\text { Heating through heat radiation, in winter condensation at window frame; } \\
\text { without window uncomfortable } \geq \text { outside heat protection required }\end{array}$ \\
\hline LL-010 & Modular configuration for tall growing plants advantageous & $\begin{array}{l}\text { Cucumber, tomato, peppers have not enough space without modular } \\
\text { configuration; tall growing plants were in higher demand by crew }\end{array}$ \\
\hline LL-011 & Metal piping would have reduced leakage & Glued connections of current design problematic \\
\hline LL-012 & Redesign piping to prevent leakage & $\begin{array}{l}\text { Pipe shape has been redesigned to avoid lower points, where water can } \\
\text { collect (U-shapes) }\end{array}$ \\
\hline LL-013 & Water recovery of AMS too small & $\begin{array}{l}\text { Plate-heat-exchanger too small, assumptions during design insufficient, } \\
\text { cooling liquid has to be on a lower temperature, more buffer for heat- } \\
\text { exchanger; more water than originally anticipated has been release } \\
\text { to atmosphere (human was not included, plants released more water, } \\
\text { condensation) }\end{array}$ \\
\hline LL-014 & Thermal system too compact for access/repairs & Placement and sizing improved \\
\hline LL-015 & Equipment sizing (esp. piping/harness) should be singular & $\begin{array}{l}\text { Especially for water recovery, change of sizing requires connectors (leak- } \\
\text { age) and introduced complex replacement situation (only one sizing) }\end{array}$ \\
\hline LL-016 & Height for racks difficult to work on & $\begin{array}{l}\text { Rack height for uppermost and lowest parts difficult to handle, make } \\
\text { trays removable to work on at work table }\end{array}$ \\
\hline
\end{tabular}

SY-DE-0060: The launch mass shall not exceed $22.800 \mathrm{~kg}$, including Docking vehicle and radiation and debris shield.

SY-DE-0090: The system shall be one failure tolerant for functions relevant to keep the plants or crew alive. SY-DE-0100: The grow area shall allow 60\% leafy plants and $40 \%$ tall growing plants.

SY-PE-0010: The system shall provide at least $25 \mathrm{~m}^{2}$ of grow area.

The abbreviations MI, DE, SY, and PE indicate "mission", "design", "system" and "performance" (requirements) respectively.

The remaining requirements focus on detailed design of subsystems (e.g. detection limit for pressure deviations), or crew safety and are also not testable in a design study, but only during implementation.

\subsection{Greenhouse structure design}

As mentioned in Sect. 2.4, the structure design was based in large parts on existing structures and structure concepts, as well as previous projects carried out by DLR and its partners.

\subsubsection{Rigid service section structure}

For the service section, which is envisioned as a rigid cylindrical structure, apt analogues are the rigid pressurized modules currently used for the International Space Station and various cargo vehicles. For the preliminary design, the Cygnus Pressurized Cargo Module was used as the reference case and a mass estimation was carried out by scaling of the service section structure dimensions with respect to this reference. 


\subsubsection{Deployable cultivation-area structure}

The design of the deployable membrane shell was adapted from previous work carried out by Arescosmo on projects.

As an adaptation from these previous designs, the functional micrometeoroid and orbital debris shielding layer was removed, to reduce the shell thickness and increase the potential packaging efficiency of the membrane shell.

A regolith cover is assumed to be available on the lunar or Martian surface, which would provide protection to the greenhouse. Thus, such a shielding layer is not needed as part of the greenhouse itself. However, to ensure that the greenhouse structure is also protected during transport, a separate removable cover is implemented, as mentioned in the design assumptions.

The membrane shell is connected on both ends to the rigid sections (the service section and a rigid interface ring), but also connects to internal rigid frames, spaced evenly along the length of the deployable section. These rigid frames are connected by hinged spacers and longerons which allow for packaging and deployment in the longitudinal direction.

To achieve the packaging required for fitting the launcher fairing, both a longitudinal and radial expansion of the membrane shell were needed. The radial expansion was needed to more optimally accommodate the plant cultivation area, by allowing for three plants cultivation racks (one on each side, with one central rack). This was considered preferable to the alternative, which would have utilized two plant cultivation racks, but would therefore require more expansion of the system in the longitudinal direction for gaining the same amount of growth area.

To accommodate the radial expansion, the rigid frames within the deployable section, which provide structural support post-deployment, were conceptualized to allow for telescopic deployment, expanding outwards and thus forcing the radial deployment of the membrane shell.

\subsection{Subsystems and accommodation}

The majority of subsystems are found in the service section. It is intended to be a separate working area, limiting interchange between greenhouse and subsystem equipment.

The overall distribution of tasks and functions is the same as in the EDEN ISS MTF, although, based on the lessons learned, some changes have been implemented, e.g. transferring the working area for handling plants and food into the greenhouse vs. the service section. This allows easier access, limits contamination risks between food and equipment and also reduces work time as food is transferred with less effort, while at the same time a larger work area could be provided.

The current configuration also provides easier access to the piping, which allows better maintenance and easier inspection for cleaning. The current idea is to use water hosing for cleaning the majority of the greenhouse - the used water will accumulate in the lower part of the greenhouse where it is collected and removed automatically for recycling.

The nutrient delivery system can, with the updated design, be accessed more easily, enabling the crew to inspect the nutrient solution.

\subsubsection{Power control and distribution system (PCDS)}

The power control and distribution system consists of the main power box, an energy measurement system, cable channels and power cables, and the internal and external lighting (excluding the plant illumination system). The main power box holds all fuses, relays, wattmeters and DC converters and splits the incoming three-phase line from the habitat into lines for each subsystem, which are then split into lines to the different components.

Each subsystem has a main fuse/switch to shut down the complete subsystem and fuses/switches for each component or a group of components within the subsystem, and a main power switch is implemented to control the power for the whole greenhouse module. All subsystems except the command and data handling system and the common equipment also have a main relay to control the whole subsystem. Single relays are built in for the components which need to be controlled by the command and data handling system.

\subsubsection{Atmosphere management system (AMS)}

The AMS counteracts the deviations (e.g. from gas exchanges, thermal loads) of the air from the nominal operational conditions by filtering and dehumidifying the air in the greenhouse. A liquid-air cooling coil is used to dehumidify air, with the recovered condensate water subsequently filtered, sterilized and pumped to the fresh water tank. One pre- and one HEPA (high efficiency particle air) filter are implemented in the design to mitigate the risk of undesirable micro-organism growth. Additionally, a volatile organic compound (VOC) filter removes trace gases, such as ethylene, from the air to prevent a build-up to the detriment of plant and crew wellbeing.

For increased plant yield, the environment will have an elevated $\mathrm{CO}_{2}$ level, which will be achieved via injection of $\mathrm{CO}_{2}$ from the habitat, either via direct air exchange or via intermediate capture and storage of $\mathrm{CO}_{2}$ in the habitat with subsequent injection in the greenhouse. The EDEN ISS MTF has a set point of $1000 \mathrm{ppm}$, although the level was often higher due to crew contribution, and this is the baseline value assumed for the future planetary greenhouse as well 
$\mathrm{O}_{2}$ levels will be monitored, but at present no methods are implemented in the AMS rack to reduce the $\mathrm{O}_{2}$ level. The baseline scenario foresees air exchange between habitat and greenhouse, which would regulate the oxygen (and $\mathrm{CO}_{2}$ ) levels.

\subsubsection{Nutrient delivery system (NDS)}

The NDS is based on the existing aeroponic system developed by DLR.

The main component racks, located within the service section, contain two nutrient solution tanks with internal primary variable speed mixing pumps. Sensors include $\mathrm{pH}$, electrical conductivity, temperature, water level and flow rate sensors.

System disinfection is realized with an integrated ozonation system. To facilitate automatic monitoring and control of the nutrient solutions, $\mathrm{pH}$ and EC probes are suspended directly in the nutrient tanks.

Stock nutrient reservoirs and acid/base control solutions are contained near the main tanks, with the corresponding dosing pumps mounted above the tanks. Both tanks have redundant sensors to ensure system reliability.

Each nutrient tank is operated independently and can have different nutrient solution compositions according to experiment and plant requirements. Each nutrient tank has two separate stock supply tanks (traditionally known as A and $\mathrm{B}$, but in this case the second tank will have solutions $\mathrm{C}$ and D available), but both are supplied from the same acid and base reservoirs for $\mathrm{pH}$ control.

In contrast to the MTF, which incorporated one highpressure pump per rack, the preliminary design here foresees two larger pumps (1 active, 1 spare) for each of the nutrient tanks. These pumps will prime pressure vessels, which pressure feed the pipes for delivery of the nutrient solution to the plants. This approach reduces the number of pumps in the system.

Return of the nutrient feed stream from the trays is by a combination of gravity return to a central lower reservoir and active pumping with submersible pumps which engage in response to water level sensors located within the sump reservoir. The entire NDS solution loop is closed (recirculating). Water lost to evaporation and transpiration is recovered by the condenser located in the AMS rack in the service section. Recovered water is directed to the fresh water tank located in the floor of the airlock. Additional water from the fresh water tank is injected into the nutrient tanks in response to the predetermined tank water level, or as required for nutrient composition control (i.e. lower EC).

\subsubsection{Thermal control system (TCS)}

The TCS employs an active cooling approach. It uses liquid cooling loops to transport heat to the main habitat. Additionally, heaters are present to ensure the temperature does not drop below $5{ }^{\circ} \mathrm{C}$ in case of subsystem failures.

The TCS actively dissipates the bulk of the heat produced inside the greenhouse. Specifically, the thermal system will dissipate the heat from the AMS and the LED panels. The AMS thermal loop and the LED thermal loop have a similar architecture. A pump with an expansion vessel forces a coolant liquid through the system (AMS dehumidifier or LED cold plate) and then towards a plate heat exchanger.

Temperature of the thermal loops is regulated by mixing the in- and backflows using three-way valves. For the AMS cooling coil, the volume flow will also be controlled via three-way valve, whereas for the LED panels flow regulation valves will manage the flow rate through the system. The transport architecture handles the opposite side of the two heat exchangers, supplying a cold coolant liquid and transporting the 'hot' coolant liquid to the habitat, with a pump and expansion vessel ensuring the desired flow rate is met and sensors providing the required data for control of the actuators.

\subsubsection{Control and data handling system (CDHS)}

The baseline design for this subsystem utilizes two PCs connected over an ethernet switch to the network. The two CDHS PCs located within the service section are the main control server PC and the camera control PC.

The main control server $\mathrm{PC}$, including redundant array of independent disks (RAID) system, is used to control and monitor all systems inside and outside the greenhouse, the safety system, and the camera system. It can also be used to visualize the control parameters on the connected screens located in the service section, to write or upload new program code to the control system and to download and store control data. The camera control PC is dedicated to processing camera images and buffering control data.

Aside from the command and data handling, and the communication components, the CDHS also comprises a safety system to ensure crew safety. This system, consisting of $\mathrm{O}_{2}$, $\mathrm{CO}_{2}$ and smoke sensors, provides visual and audio cues within the greenhouse and relevant information is transmitted to the habitat and the control room on Earth.

\subsubsection{Illumination system (IS)}

The Illumination System consists of the LED panels which shall be installed in the greenhouse. For initial sizing, the 
Table 5 Mass budget for the overall system, including a 20\% system margin in $\mathrm{kg}$

\begin{tabular}{ll}
\hline Subsystem & Mass $(\mathrm{kg})$ \\
\hline Docking stage & 2650 \\
Structure $^{\mathrm{a}}$ & 8173 \\
Atmosphere management system $^{\text {Nutrient delivery system }}$ & 884 \\
Thermal control system & 766 \\
Illumination system & 990 \\
Control and data handling system & 900 \\
Power control and distribution System & 691 \\
Misc & 680 \\
Total & 65 \\
Total with 20\% system margin & 15,799 \\
\hline
\end{tabular}

${ }^{a}$ Structure mass covers primary, secondary and tertiary structural elements

${ }^{\mathrm{b}}$ General lighting, as well as the tray cleaning and check system (Dishwasher)
LED panel per tray. For future development work, a more detailed consideration will be made regarding the use of water-cooled versus air-cooled LED units.

\subsection{System summary}

Based on the extrapolation of the subsystems, their masses have been determined and summarized. Including a $20 \%$ system margin, a total of $18,959 \mathrm{~kg}$ has been estimated as overall mass.

A detailed summary is given in Table 5. It can be seen that the structure has the largest contribution, more than $50 \%$ of the total mass. The second largest contribution to the system mass is the docking stage. The remaining systems are all below $1000 \mathrm{~kg}$.

Overall, 28 trays for tall plants have been foreseen and 76 trays for small plants (each tray has a growth area of 0.328 $\mathrm{m}^{2}$ ), positioned in several levels above each other. In total

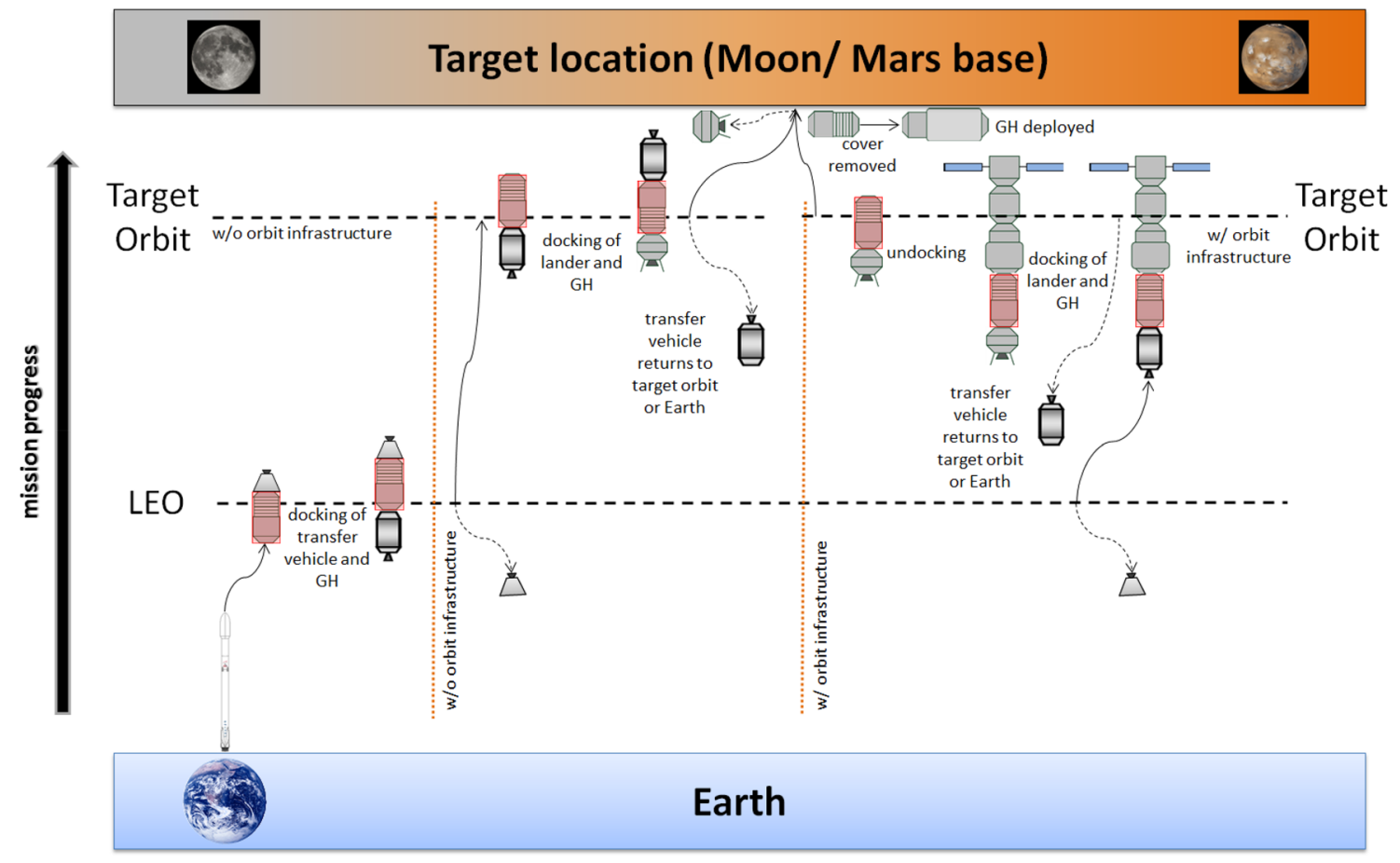

Fig. 4 The mission sequence as assumed for the operation of the greenhouse, its launch, docking, transfer and landing. A dedicated transfer vehicle docks with the greenhouse. In case an orbital infrastructure (e.g. LOP-G) is present (right) the docking stage is released and the spacecraft docks with the infrastructure. Subsequently, transfer vehicle detaches and e.g. returns to Earth. A lander vehicle docks with the greenhouse for safe landing on the lunar or Martian surface.
In case of no present orbital infrastructure, the docking stage detaches and a lander docks with the greenhouse, before the transfer vehicle detaches and returns to Earth. In both cases after landing, the lander is detached (possibly returning to orbit or the infrastructure) and the greenhouse cover is removed. Afterwards the greenhouse is deployed and prepared for operation

of ca. $30 \mathrm{~m}^{2}$ of growth area have been included. The design is flexible and could be adapted to a different tray layout. 


\subsection{Overall mission scenario}

Based on assumptions about the missions scenario (see Sect. 2.2), an overall mission scenario has been derived, pictured in Fig. 4. For this purpose, a docking stage has been envisioned to allow the module to act as a passive target for docking (i.e. a determined attitude and position are possible).

The scenario can be summarized to the following steps:

1. Deployment of the module into low earth orbit (LEO) via Launcher (e.g. Falcon 9).

2. Utilizing a stage called docking stage, the greenhouse module is stabilized in position and attitude for docking with the transfer vehicle, assumed to exist.

3. The module is approached by the transfer vehicle, which docks to it.

4. The transfer vehicle transports the module to its destination (either towards a target infrastructure in the target's orbit or directly to orbit).

5. A landing vehicle docks with the greenhouse module and lands it on the target surface.

6. The greenhouse module is transported to the desired location on the surface.

7. Upon arrival the greenhouse's protection cover is removed.

8. The greenhouse module is attached to the existing habitat and covered by regolith for thermal, radiation and debris protection.

9. The expandable greenhouse module is deployed on the surface and extends to its full length.

10. The deployed section is fitted with all remaining equipment and the plant seedlings.

11. All subsystems and functionalities are tested.

12. The greenhouse begins producing food.

Although a detailed design of the docking stage is outside the scope of this study, some information, in particular concerning the mass, is required to assess the feasibility of a single launch mission scenario. Since, in effect, the docking stage will perform most of the functions currently carried out by cargo vehicles such as Dragon and Cygnus, the latter served as basis for this vehicle.

The Cygnus spacecraft, shown in Fig. 5, consists of a (pressurized) cargo area and a service module. The mass of the service module is $1700 \mathrm{~kg}$ [10]. The pressurized cargo module can be replaced by a lightweight radiation and a micro meteoroid and orbital debris (MMOD) shield.

As a first estimate, such an MMOD shield can be based on the Mars TransHab shield design [21]. This has a thickness of approximately $30 \mathrm{~cm}$ and the areal density is estimated to be $\sim 10 \mathrm{~kg} / \mathrm{m}^{2}$, which should suffice for

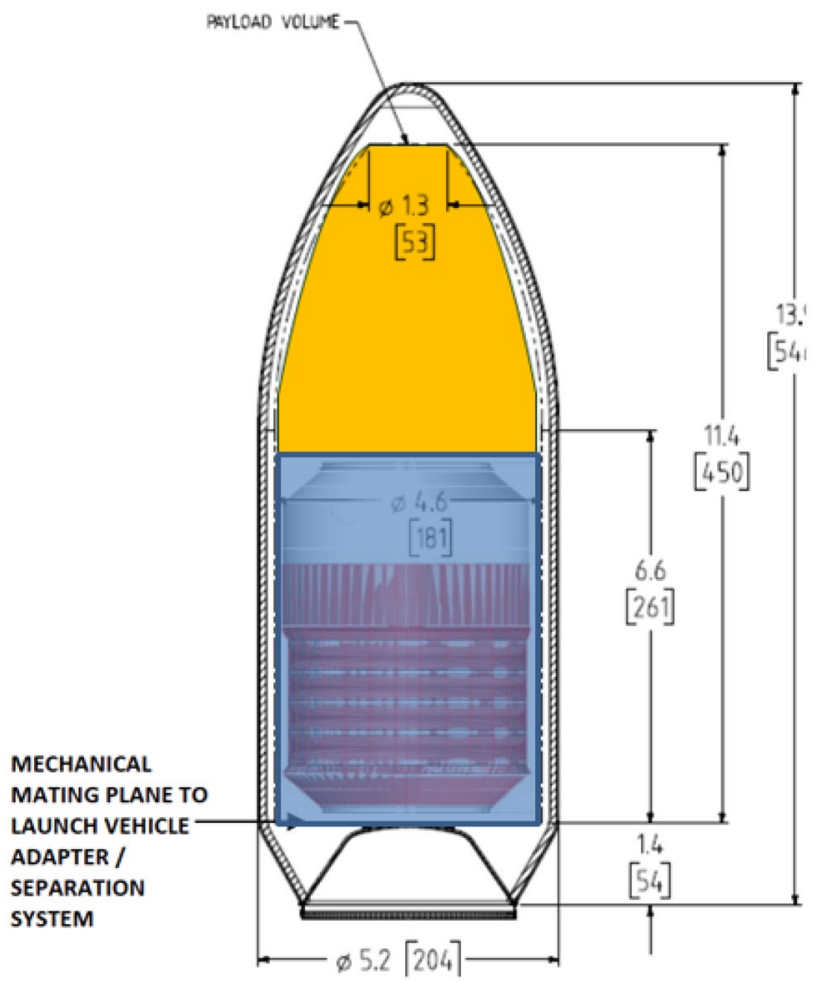

Fig. 5 Fairing dimensions of Falcon 9 (in meters, with inches in brackets) as compared to the design of the greenhouse module, incl. cover (blue hue, ca. $30 \mathrm{~cm}$ thick) and the remaining volume for the docking stage (orange). Based on [20]

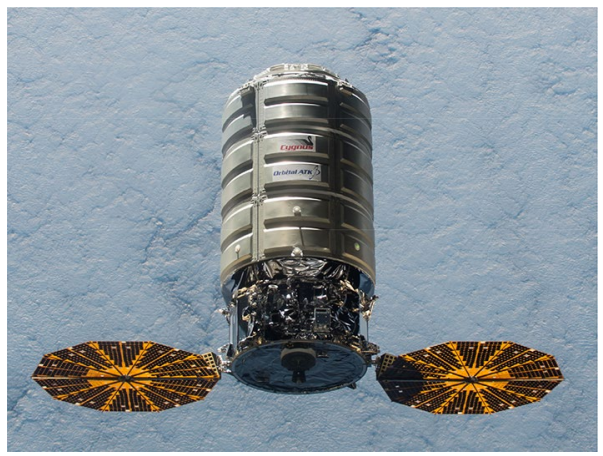

Fig. 6 Enhanced Cygnus spacecraft in LEO [Image: NASA, public domain]

small to medium size particle impacts [22]. Assuming a length of $6.6 \mathrm{~m}$ and an outer diameter of $4.6 \mathrm{~m}$, as per the dimensions of the Falcon 9 payload fairing (see Fig. 6), the mass of the MMOD shield is around $950 \mathrm{~kg}$.

The total mass of the docking stage can thus be estimated at around $2650 \mathrm{~kg}$. Accounting for the uncertainty in the design with a $20 \%$ margin, the mass is $3180 \mathrm{~kg}$. 


\section{Discussion}

\subsection{Requirements}

Besides the detailed technical requirements and requirements ensuring crew safety, the requirements-as listedensure that the design assumptions are resembled in the design. The requirements have been derived from the greenhouse functions, but also from the lessons learned from the prototype test in Antarctica and from the mission scenario (e.g. the launcher availability).

To limit the launch costs, it is required to have a single launch (MI-DE-0010) and thus the design needs to match current launchers, in size and mass. The single launch scenario also reduces system complexity, by reducing the number of interfaces as compared to a mission with multiple modules.

One main driver for the design has been requirement SY-DE-0010, which is intended to reduce the amount of workload necessary to bring the greenhouse to operation. This required a rigid part where relevant equipment for the subsystems can be installed even before launch. The remaining internal equipment (e.g. air ducts) is deployable just like the outer greenhouse shell and the internal frames.

While tests of functionality would be required before commencing operation and minor adjustments and e.g. connections between subsystems might be necessary, especially also between greenhouse and main habitat, this compact design allows commencing operation with as little crew-time as possible.

The envelope of the system (SY-DE-0020) has been selected to allow the existing Falcon 9 launcher as launch vehicle. This way it can be ensured that the system can be launched even if currently planned launchers (e.g. SLS) are not available or are delayed. In case SLS becomes available, the design can be scaled up. For similar reasons, SY-DE-0060 limits the total launch mass to $22.8 \mathrm{mt}$ (metric tons), which can be launched into LEO by Falcon 9.

Thermal control is handed over to the main habitat, based on the assumption of an existing infrastructure, which is e.g. consisting of a heat, radiation and debris shield made from regolith on site. Radiators of the base need to transfer heat outside this shield or possibly transfer the heat into the ground with a common concept for the overall base.

To justify the development and transport of the greenhouse, a minimum operation time of 2 years (SY-DE-0050) was set. This mostly affects reliability of components. Depending on the actual budget available, this number can be increased.

As the greenhouse will be part of the life-support system, it should be at least one failure tolerant. This was accounted for in the design by including two or more components of the same kind where necessary.

Based on the lessons learned (LL-010), more focus on tall growing plants shall be provided (SY-DE-0100), e.g. tomatoes, as they are in higher demand by the crew. Yet, the design allows reconfiguration of the internal layout, i.e. based on a nutrition plan for the crew, the configuration of the growth area can be adapted (either increasing or decreasing the growth area).

The requirement concerning the growth area (SY-PE0010) has been exceeded by approx. $20 \%$ due to an efficient design concerning accommodation. The rationale has been to at least provide twice the amount of growth area in comparison to the original prototype, exploiting technical advances. Based on crew feedback from the Antarctic operations phase, this would provide sufficient fresh food to supplement the crew diet, without overproducing and leading to food spoilage. Further improvement could be gained in case of an increase of the envelope and launch mass (i.e. heavy launchers like SLS become available), at an increase of launch costs however. The authors do not expect the growth area to be sufficient for a crew diet alone. Currently, it is expected that the greenhouse will only produce fresh food as an addition to the total diet, while also serving as part of the life-support system. Integrating several of these greenhouse modules into the base architecture would enable higher cultivation areas, eventually enabling fulfilment of $100 \%$ of the crew dietary needs.

\subsection{Adapted design}

The EDEN ISS MTF design was restricted by the dimensions of two $20 \mathrm{ft}$ high-cube shipping container. Especially, the relatively narrow interior width of only $2.15 \mathrm{~m}$ had a strong influence on the layout of the subsystems and the plant cultivation area. The larger width/diameter of the greenhouse design presented in this paper allowed a better positioning of subsystems and cultivation racks.

The five meter diameter of the inflatable greenhouse section makes three rows of plant cultivation racks possible while still allowing a comfortable aisle width for working and moving around.

The larger width and height of the service section of the space greenhouse concept compared to the MTF design gives more room for positioning of the subsystems. The space below and on top of the central aisle is large enough to house the complete AMS and its air ducts. In the MTF the AMS was built as an upright rack, which made connecting the air ducts to the greenhouse space challenging.

Compared to the MTF with its single NDS rack, two of those racks are envisioned for the space concept. One is positioned on either side of the aisle of the service section. 
Table 6 Calculation of possible crop yield of example plant selection

\begin{tabular}{|c|c|c|c|c|c|}
\hline Crop & $\begin{array}{l}\text { Average growth } \\
\text { cycle length }(d)\end{array}$ & $\begin{array}{l}\text { Average edible fresh } \\
\text { weight }(\mathrm{g} / \text { tray })\end{array}$ & $\begin{array}{l}\text { Time normalized average edible } \\
\text { fresh weight }[\mathrm{g} /(\text { day tray })]\end{array}$ & $\begin{array}{l}\text { Number of } \\
\text { trays }\end{array}$ & $\begin{array}{l}\text { Fresh } \\
\text { weight (g/ } \\
\text { day) }\end{array}$ \\
\hline \multicolumn{6}{|l|}{ Lettuce and leafy greens } \\
\hline Batavia & 38 & 512.53 & 13.44 & 6 & 80.66 \\
\hline Expertise & 38 & 780.94 & 20.53 & 6 & 123.15 \\
\hline Outredgeous & 37.85 & 687.84 & 18.30 & 6 & 109.78 \\
\hline Waldman's Green & 37.91 & 907.5 & 24.91 & 6 & 149.46 \\
\hline Arugula & 29 & 1799.41 & 61.63 & 6 & 369.76 \\
\hline Red mustard-frizzy lizzy & 82.67 & 2929.2 & 35.26 & 6 & 211.53 \\
\hline Red mustard—red Giant & 82.67 & 3536.8 & 42.62 & 6 & 255.74 \\
\hline Swiss Chard & 90 & 3037.63 & 33.59 & 6 & 201.53 \\
\hline Mizuna & 119 & 7578.8 & 63.69 & 6 & 382.12 \\
\hline \multicolumn{6}{|l|}{ Herbs } \\
\hline Basil—Dolly & 121 & 2392.85 & 19.8 & 4 & 79.19 \\
\hline Parsley & 266 & 5399.4 & 20.3 & 4 & 81.19 \\
\hline Chives & 266 & 4582 & 17.23 & 4 & 68.90 \\
\hline \multicolumn{6}{|l|}{ Fruits } \\
\hline Cucumber-Picowell & 161 & $16,689.93$ & 105.37 & 5 & 526.84 \\
\hline Tomato-Orange F1 3496B & 286 & 4285.3 & 14.98 & 9 & 134.85 \\
\hline Tomato-Cherry F1 1202 & 286 & 4888.2 & 17.09 & 9 & 153.82 \\
\hline \multicolumn{6}{|l|}{ Tubers } \\
\hline Radish-Lennox & 22.6 & 436.89 & 19.33 & 5 & 96.65 \\
\hline Radish—Raxe & 23 & 596.59 & 25.73 & 5 & 128.65 \\
\hline Kohlrabi & 58.71 & 2660.62 & 46.38 & 5 & 231.90 \\
\hline
\end{tabular}

This allows for better positioning of the feed and drain lines from the NDS to the greenhouse section and back.

In the MTF service section the working desk has to function as working desk for computer operations, crop sowing, cleaning of equipment and many more tasks. A small trolley is positioned in the FEG to function as working table. In the space concept a relatively large working table was included in the greenhouse section design, allowing for more tasks (e.g. sowing, weighting of crops) to be conducted directly inside the greenhouse instead of the service section. This design change also frees up space for a (smaller) dedicated working desk with access to the CDHS screens inside the service section design of the space concept.

\subsection{Expected crop yield}

The crop yield for the presented design will greatly depend on the actually selected crops and the overall mission scenario. However, some estimates can be made.

Given the increase of the growth area by a factor of 2.464 , a similar factor can be assumed for the crop yield if identical crops are selected as for the EDEN ISS operations phase. Therefore, for a similar crop selection approx. $2.26 \mathrm{~kg}$ of crops can be assumed to be produced per day. For a six person crew, this would equal $376 \mathrm{~g}$ of fresh produce per person each day on average (considering growth cycles, this yield is normally not available every day). This calculation includes the non-optimal plant growth from the EDEN ISS mission (e.g. the lack of yield from sweet pepper). Assuming more optimized plant growth the yield can be further increased.

With the tray number as foreseen in the configuration presented here, i.e. 76 trays for small growing plants and 28 for tall growing plants, a sample crop yield could produce about $3.4 \mathrm{~kg}$ of food (fresh weight) per day with an example plant selection as given in Table 6 . This calculation is based on average yields and growth cycle lengths from the EDEN ISS mission as well as the available growth area $\left(0.328 \mathrm{~m}^{2}\right.$ per tray). Lettuce and leafy greens comprise about $55 \%$ of the fresh weight, the fruity crops account for roughly $24 \%$ and tubers comprise $13.5 \%$. The remaining fresh mass is provided by herbs.

It should be noted that the crops selected during the EDEN ISS mission have been selected for test purposes and not based on an optimized nutrition plan for the crew. Further research would be necessary to determine best crop selection based on technical, nutrition and life-support system needs. 
Within the EDEN ISS project, a method for crop selection has been applied, evaluating plant cultivation aspects (e.g. required height, harvest number, handling effort), human factors (e.g. if the plant is edible, taste, texture) and yield (e.g. light, energy usage efficiency). A two-step selection process was used, including a decision tree, pairwise comparison and 0,1,2-method, to create a list of crop candidates. Weighting the criteria delivered a score for each crop [14]. This scoring has been based on assumptions and needs to be revised once further research and experience is available. Therefore, the crop selection has not been a driver for the system design presented here, keeping the design flexible for any variety of crops.

The nutritional value has not been a factor for the selection process, as the pick-and-eat crops under consideration for the EDEN ISS mission typically have low values.

Besides the fact that transporting large amounts of food towards a long-term mission goal is costly, due to the involved effort (e.g. transfer from Earth to Moon or Mars), it is also ineffective to store food for long durations, justifying on-site production further. Mostly the food quality and the nutritional content (nutrient stability, vitamin content) deteriorate over time [12]. So even if the crop yield is not sufficient to supply all needed calories, it can supply the crew with vitamins (e.g. B1, K), nutrients (e.g. potassium), antioxidants and phytochemicals, which cannot be obtained by the crew via food stored for long durations ( $>3$ years) [12].

\subsection{Design plausibility}

The design presented here is generic and does not consider specific environmental conditions on Moon or Mars. While at first glance this might appear to be a limitation of the design, the design is actually versatile by assuming a black box for the actual main habitat.

Considering that a habitat would exist before a greenhouse is established, it makes sense to assume that this habitat and its infrastructure would provide the specific means of protection. Thermal control of the overall habitat has to be achieved - with different loads-on Moon and Mars. However, by assuming the greenhouse will be attached to the main habitat, handling these functions, the greenhouse itself becomes independent in design.

Especially radiation and debris protection can use similar means on Moon and Mars: regolith covers. How exactly these are realized is also independent of the greenhouse design and means for that have to be in place in any case as all habitat parts will rely on that. One possible scenario would be using existing caves, which would be adequate for either environment, Moon or Mars, and is not a driver for any module design. It is simply a matter of finding a cave with enough space for accommodating the whole base.
Reducing the number of critical parts of the nutrient delivery system, especially the pumps, reduces the number of expected component failures and thus the required amount of spare components and repair and maintenance work as well as overall risk of failure. The pumps have proven to be particularly prone to failure. While space rated equipment would possibly be less vulnerable to equipment failure, potential contamination by dust/ regolith still increases the risk of failure of equipment with moving parts, therefore they have been reduced in number.

The operation of the greenhouse is intended to be extendable. While the presented design greenhouse module is supposed to operate on its own in the presented mission scenario, depending on the amount of food to be created, several such modules can be integrated into the base architecture to increase crop production capabilities.

The design presented here allows a growth area increase by more than a factor 2 compared to the EDEN ISS Mobile Test Facility, even when including, relatively, more growth area for tall plants than the FEG deployed in Antarctica.

The limitation of dimensions and launch mass to sizes and performance of an existing launcher and its fairing provides credibility concerning launch opportunities. Independent of the possible availability of a future launcher, i.e. SLS, current heavy launchers can accommodate the design and transfer it into low Earth orbit, especially Falcon 9, which has been used as envelope for the fairing and can service the expected launch mass of the greenhouse plus the docking stage and cover.

In case of an unplanned increase of the launch mass (e.g. if a dedicated transfer stage has to be included in the launch with the module), Falcon 9 Heavy could serve as an alternative, however this would increase costs.

In case SLS does become available, the design could possibly be used as one of two or more payloads, i.e. it would still fit.

Once these heavy launchers are available launching this greenhouse module would become more reliable as well, even if design changes are necessary.

Just like the Space Shuttle System has been a major enabler for the International Space Station, it is reasonable to assume that some kind of infrastructure will be installed to enable the construction, re-supply and enhancement of a human base on Mars or Moon, e.g. similar to NASA's Deep Space Transport [23], equipped with an efficient electrical engine, capable of transferring cargo between Earth and the respective destination.

A series of regular flights for operating and maintaining a crewed lunar or Martian base, would require a reliable vehicle to transfer modules, cargo and crew to keep costs moderate-in comparison to a mission architecture requiring a unique transfer stage for each flight. 
Therefore, the assumption of a dedicated transfer vehicle is reasonable and therefore the presented design does not require an own propulsion system.

\subsection{Comparison to other concepts}

There are two other notable inflatable space greenhouse concepts. Firstly, the Lunar Greenhouse (LGH) concept from the University of Arizona [24] and secondly, the Astro Garden System by Orbitec SNC [25].

The LGH concept foresees four inflatable greenhouse modules connected to a lunar habitat. The inflatable modules only house the plant cultivation area, while the majority of the subsystems are housed in a separate module. The inflatable modules have a diameter of around $2 \mathrm{~m}$ making them much smaller than the space greenhouse concept presented in this paper. Consequently, more modules are required to meet certain production requirements. The LGH concept has been under development already for more than ten years. Two ground test prototypes exist. A system called 'wire cultivation' is used to grow the plants, with the plants standing in narrow foil channels suspended from wires.

A ground test prototype of the Astro Garden System is currently being built. The system uses aeroponics to supply the crops with water and nutrients, similar to the concept of this paper. The Astro Garden System does not use a rack structure like the EDEN concept, but rather consists of a number of cultivation compartments that can be orientated independently. Although the Astro Garden System is not a complete greenhouse module concept, it is envisioned to incorporate this cultivation system into an inflatable module. The design of the Astro Garden System already foresees to have the system collapsible during launch to reduce its volume roughly by a factor of two.

Greenhouses for analog tests exist at e.g. Devon Island [26] and at the Mars Desert Research Station in Utah [27]. The latter is basically an ordinary greenhouse [27], with only rudimentary systems, whereas the former is used for automation research of greenhouses in extreme environments [26]. Yet, none of the two are tests of prototypes, which will directly be evolved into a to-be-deployed space system.

In Antarctica several greenhouse systems have been deployed in the past, nine are currently in operation [2]. Yet, while Antarctica is a suitable test-ground for space greenhouses, e.g. due to similar isolation of the crew (and thus e.g. benefiting from fresh food and the presence of other living organisms), difficult supply chains and similarly strict protocols concerning site protection (i.e. preventing pollution), previous greenhouses have not been used as research objects for space systems [2]. EDEN ISS MTF has been the first dedicated test facility for space hardware in Antarctica. This makes the derivation of the presented design unique among theoretical designs presented in the past.

\subsection{Fitting to current mission plans}

Currently no finished plan exists for future human exploration. While the NASA Design Reference Mission Architecture for Mars missions does not contain a design for a greenhouse, it clearly states the goal of "providing crew needs from local resources. An example of this is in-situ food production" [28].

The presented design provides a concept for just that. Detaching the design from the specifics of the environment by assuming the environment specific thermal and radiation loads are handled by either the main habitat or e.g. regolith covers, makes it versatile. Thus, its fitness to any mission plan involving Moon or Mars is increased, making the design robust for any change of plans in destination. Also, in case of a subsequent deployment, the design used on Moon could also be used on Mars, building on its heritage and experience of using the system.

In particular for long duration missions where dependence on resupply from Earth should be minimized, if not eliminated, greenhouse modules provide additional benefits when incorporated into the life support system of the base, by facilitating air revitalization and water treatment.

Having a greenhouse module which is separate from the habitat, as opposed to designs which incorporate plant cultivation inside the habitat, will allow for more optimal environmental control in the distinct (functional) areas of the base by making it possible to tailor the conditions in the living quarters towards optimal crew comfort, while simultaneously providing the environment for plants to thrive.

While it would be possible to implement a closed-loop plant cultivation facility within a habitat module, this would require that the habitat itself is significantly larger in order to accommodate the greenhouse along with crew quarters and other facilities. It is more likely that smaller modules would be utilized in the initial construction of a lunar or Martian base for compatibility with a larger selection of launch vehicles.

\section{Open issues}

The design presented in this paper is only a first design, derived from an existing Antarctic greenhouse. Numerous elements require further development for implementation.

Three aspects concerning the internal subsystems are especially relevant.

\subsection{Gas exchange system}

The integration of a greenhouse into the life support system of a habitat, or planetary base, can provide significant benefits but also comes with a number of challenges. In particular, the 
air exchange between the habitat and the greenhouse, in order to optimally benefit from the natural processes of plants, has to be studied in further detail.

In previous design studies the possibility of periodic direct air exchange between habitat and greenhouse was considered. In that case oxygen-rich air is vented to the habitat and carbon dioxide-rich air is provided to the greenhouse. An alternative to such a system could be the implementation of $\mathrm{CO}_{2}$ and $\mathrm{O}_{2}$ capture and storage systems, with dedicated supply systems transporting the captured gases to the desired location.

A detailed trade-off needs to be done on the different options as early in the design process as possible.

\subsection{Nutrient delivery system}

The nutrient delivery system with pressurized tanks instead of dedicated pumps as included in this design has not been tested yet in the EDEN ISS MTF or in the laboratories of the project partners. A test system should be developed as soon as possible to determine whether or not the expected benefits occur and to assess potential unforeseen disadvantages and operational challenges.

The results of this test should be used to review the nutrient delivery system design.

Currently, the design contains redundancy without need of parts replacement. Due to the high pressure involved for operation, it has been regarded as reasonable to include replacement pressure tanks. This way valves and attachments can be designed to be permanent-and thus more reliable and stable. In case one of the pressure tank systems fails, another is used.

\subsection{Usage of natural light}

Currently, the design does not foresee the use of natural light for nurturing the plants. This is mainly due to the assumption of a regolith cover deployed over the greenhouse module for insulation and also due to the lunar night lasting approx. 14 days.

Estimates of designs show that the equivalent system mass of greenhouses supported by natural light can be reduced by $45 \%$ [26].

Therefore, it should be investigated if and how natural light could be used for the current design in future work.

Furthermore, there are three aspects concerning the deployable structure that need further analysis and research.

\subsection{Stowing and deployment of the primary structure}

The packaging ratio which was assumed in this preliminary design needs to be analysed and verified as soon as possible using simulation tools and (small scale) testing.
In case the envisioned stowed dimensions cannot be obtained either the structure dimensions, and thus the available cultivation area, will need to be reduced or a larger launch envelope needs to be provided to enable a single launch scenario.

The development effort needs to focus on the telescopic deployment of the flanges, as well as the packaging and deployment of the membrane shell, along with the impact of the secondary structure elements (e.g. floor panels) on the packaging and deployment strategy.

\subsection{Material selection and detailed load analysis}

While some material selection has been carried out for the membrane structure of the greenhouse, the same still needs to be done for the rigid elements. A significant mass reduction could be possible if a lightweight carbon fiber reinforced polymer (CFRP) or alternative material were incorporated into the design.

Coupled with this material selection, a detailed load analysis is required to optimize the structure's thickness and mass, as the preliminary sizing was done based on existing structures and various reference concepts, or, in the case of the rigid frames and longerons, on very conservative estimates.

In some cases, the material selection process may require characterization testing to determine behavior under, or response to, expected internal and external factors.

\subsection{Hatch and interface design}

As the internal subsystem design develops, the interfaces to the habitat need to be clarified. These interfaces need to be integrated into the rigid structure design, while simultaneously the ability to connect to a docking module and a transfer vehicle needs to be implemented.

Two open issues concern the assumptions about the docking stage:

The debris environment and impact probabilities need to be analysed in detail to determine whether or not the shield requires adaptation for the change in environment. Also, it may be the case that the transfer vehicle provides radiation and debris protection for the greenhouse after docking, in which case the docking stage might not need to provide an MMOD shield.

\section{Conclusion}

The EDEN ISS MTF is a greenhouse system that has been developed as a prototype for a planetary space habitat. It has been deployed at the Antarctic Neumayer III station to conduct a system test in a harsh space-analog environment. 
Utilizing lessons learned concerning its development, construction and operation, a deployable greenhouse system for operation on Moon or Mars has been adapted from the original design.

Current launchers can lift the greenhouse module with a total estimated mass of about $19 \mathrm{mt}$ (metric tons) into low Earth orbit, with capacity to spare to include a docking stage. Further handling is assumed to occur with an infrastructure dedicated to a respective programme, e.g. a transfer stage between LEO and lunar orbit.

The design is plausible and fits current mission plans. It has a simple and robust architecture, making it versatile and adaptable to future changes in mission plans.

The growth area is around $30 \mathrm{~m}^{2}$, with an emphasis on tall growing plants, based on the crew needs as experienced during EDEN ISS MTF operations phase.

Deriving the presented design from an existing greenhouse has been helpful, due to the gained experience. The analog testing allowed improvement of design and the underlying processes of operating the greenhouse and thus improved the space greenhouse design profoundly.

Acknowledgements Open Access funding provided by Projekt DEAL. The EDEN ISS project has received funding from the European Union's Horizon 2020 research and innovation program under Grant agreement No. 636501.

Open Access This article is licensed under a Creative Commons Attribution 4.0 International License, which permits use, sharing, adaptation, distribution and reproduction in any medium or format, as long as you give appropriate credit to the original author(s) and the source, provide a link to the Creative Commons licence, and indicate if changes were made. The images or other third party material in this article are included in the article's Creative Commons licence, unless indicated otherwise in a credit line to the material. If material is not included in the article's Creative Commons licence and your intended use is not permitted by statutory regulation or exceeds the permitted use, you will need to obtain permission directly from the copyright holder. To view a copy of this licence, visit http://creativecommons.org/licenses/by/4.0/.

\section{References}

1. Schubert,D., Bamsey, M., Zabel, P., Zeidler, C., Vrakking, V.: Status of the EDEN ISS greenhouse after on-site installation in Antarctica. In: 48th International Conference on Environmental Systems, 8-12 July 2018, Albuquerque

2. Bamsey,M., Zabel, P., Zeidler, C., Gyimesi, D., Schubert, D.: Review of Antarctic greenhouses and plant production facilities: a historical account of food plants on the ice. In: 45th International Conference on Environmental Systems, 12-16th July, Bellevue, Washington (2015)

3. Zeidler, C., Vrakking, V., Bamsey, M., Poulet, L., Zabel, P., Schubert, D., Paillé, C., Mazzoleni, E., Domurath, N.: Greenhouse module for space system: a lunar greenhouse design. Open Agric. 2(1), 116-132 (2017)

4. Nitta, K., Otsubo, K., Ashida, A.: Integration test project of CEEF. Adv. Space Res. 26(2), 335-338 (2000)
5. Lane,H.: Introduction. In: isolation NASA experiments in closedenvironment living - advanced human life support enclosed system final report, pp. 7-15. American Astronautical Society (2003)

6. Lasseur, C., Paillé, C., Lamaze, B., Rebeyre, P., Rodriguez, A., Ordonez, L., Marty, F.: MELISSA: overview of the project and perspectives. SAE Technical Paper Series (2005)

7. Dixon,M.: Controlled environment systems research facility. In: AgroSpace workshop, Sperlonga (2010)

8. Guo, S., Tang, Y., Zhu, J., Wang, X., Yin, Y., Feng, H., Ai, W., Liu, X., Qin, L.: Development of a CELSS experimental facility. Adv. Space Res. 41, 725-729 (2008)

9. Zabel, P., Bamsey, M., Schubert, D., Tajmar, M.: Review and analysis of over 40 years of space plant growth systems. Life Sci. Space Res. 10, 1-16 (2016)

10. Culbertson, F. L.: Orbital Sciences Corporation (OSC). In: Commercial Cargo Operations for the ISS (2014)

11. Anderson, M., Barta, D., Douglas, G., Motil, B., Massa, G., Fritsche, R., Quincy, C., Romeyn, M., Hanford, A.: Key gaps for enabling plant growth in future missions. In: AIAA Space and Astronautics Forum and Exposition, 12-14th September, Orlando (2017)

12. Monje, O., Nugent, M., Hummerick, M., Dreschel, T., Spencer, L., Romeyn, M., Massa, G., Wheeler, R., Fritsche, R.: New frontiers in food production beyond LEO. In: 49th International conference on environmental systems, 7-11th July, Boston (2019)

13. Perchonok, M.H., Cooper, M.R., Catauro, P.M.: Mission to Mars: food production and processing for the final frontier. Annu. Rev. Food Sci. Technol. 3, 311-330 (2012)

14. Dueck, T., Kempkes, F., Meinen, E., Stanghellini, C.: Choosing crops for cultivation in space. In: 46th International Conference on Environmental Systems, Vienna (2016)

15. Martelo Gomez, A., Jahnke, S., Braukhane, A., Quantius, D., Maiwald, V., Romberg, O.: Statistics and evaluation of 60+ concurrent engineering studies at DLR. In: 68th International Astronautical Congress, 25-29 September 2017, Adelaide

16. Zabel, P., Zeidler, C.: EDEN ISS: a plant cultivation technology for spaceflight. In: Handbook of Life Support Systems for Spacecraft and Extraterrestrial Habitats. Springer (2019)

17. Jahnke, S., Maiwald, V., Philpot, C., Quantius, D., Romberg, O., Seboldt, W., Vrakking, V., Zeidler, C.: Orbital hub: a concept for human spaceflight beyond ISS operations. CEAS Space J. 10, 355-379 (2018)

18. International Council on Systems Engineering.: INCOSE Systems Engineering Handbook, version 2a (2004)

19. NASA.: Systems Engineering Handbook, Rev2 (2007)

20. Space X.: Falcon 9 Launch Vehicle Payload User's Guide, Revision 1 (2008)

21. de la Fuente, H., Raboin, J. L., Spexarth, G. R., Valle, G. D.: TRANSHAB: NASA's large-scale inflatable spacecraft. In: AIAA Space Inflatables Forum, Structural Dynamics and Materials Conference, 3-6th April, Atlanta (2000)

22. Christiansen, E.L., Kerr, J.H., De la Fuente, H.M., Schneider, W.C.: Flexible and deployable meteoroid/debris shielding for spacecraft. Int. J. Impact Eng. 23, 125-136 (1999)

23. Connolly,J.: Deep Space Transport (DST) and Mars Mission Architecture. NASA Mars Study Capability Team (2017)

24. Sadler, P. D., Giacomelli, G., Patterson, R. L., Kacira, M., Furfaro, R., Lobascio, C., Boscheri, G., Lamantea, M., Grizzaffi, L., Rossignoli, S., Pirolli, M., DePascale, S.: Bio-regenerative life support systems for space surface applications. In: 41 st International Conference on Environmental Systems, 17-21 July, Portland (2011)

25. Moffatt, S. A., Morrow, R. C., Wetzel, J. P.: Astro GardenTM Aeroponic plant growth system design evolution. In: 49th International Conference on Environmental Systems, 7-11 July, Boston (2019) 
26. Bamsey, M., Berinstain, A., Graham, T., Neron, P., Giroux, R., Braham, S., Ferl, R., Paul, A.L., Dixon, M.: Developing strategies for automated remote plant production systems: environmental control and monitoring of the Arthur Clarke Mars Greenhouse in the Canadian High Arctic. Adv. Space Res. 44, 1367-1381 (2009)

27. Poulet, L., Doule, O.: Greenhouse automation, illumination and expansion study for Mars Desert Research Station. In: 65th International Astronautical Congress, 29th September-3rd October, Toronto (2014)
28. Drake, B. G. (2009) Human exploration of Mars Design Reference Architecture 5.0, NASA report

Publisher's Note Springer Nature remains neutral with regard to jurisdictional claims in published maps and institutional affiliations. 